\title{
Article \\ Clinical Characteristics and Outcome of Patients with Suspected COVID-19 in Emergency Department (RESILIENCY Study II)
}

\author{
Alessandro Russo ${ }^{1, *(D)}$, Elio Gentilini Cacciola ${ }^{2}$, Cristian Borrazzo ${ }^{2} \mathbb{D}$, Valeria Filippi ${ }^{2}$, Tommaso Bucci ${ }^{3}$, \\ Francesco Vullo $^{4}$, Luigi Celani ${ }^{2}$, Erica Binetti ${ }^{2}$, Luigi Battistini ${ }^{2}$, Giancarlo Ceccarelli ${ }^{2}$ (D), Maria Alessandroni ${ }^{5}$, \\ Gioacchino Galardo ${ }^{5}$, Claudio Maria Mastroianni ${ }^{2}$ iD and Gabriella d'Ettorre ${ }^{2}$ (D)
}

\section{check for} updates

Citation: Russo, A.; Gentilini Cacciola, E.; Borrazzo, C.; Filippi, V.; Bucci, T.; Vullo, F.; Celani, L.; Binetti, E.; Battistini, L.; Ceccarelli, G.; et al. Clinical Characteristics and Outcome of Patients with Suspected COVID-19 in Emergency Department (RESILIENCY Study II). Diagnostics 2021, 11, 1368. https://doi.org/ 10.3390/diagnostics11081368

Academic Editor: João Perdigão

Received: 30 May 2021

Accepted: 28 July 2021

Published: 29 July 2021

Publisher's Note: MDPI stays neutral with regard to jurisdictional claims in published maps and institutional affiliations.

Copyright: (c) 2021 by the authors. Licensee MDPI, Basel, Switzerland. This article is an open access article distributed under the terms and conditions of the Creative Commons Attribution (CC BY) license (https:/ / creativecommons.org/licenses/by/ $4.0 /)$.
1 Department of Medical and Surgical Sciences, Infectious and Tropical Disease Unit, "Magna Graecia" University of Catanzaro, 88100 Catanzaro, Italy

2 Policlinico “Umberto I", Department of Public Health and Infectious Diseases, "Sapienza” University of Rome, 00185 Rome, Italy; Gentilini.1979701@studenti.uniroma1.it (E.G.C.); cristian.borrazzo@uniroma1.it (C.B.); valeria.filippi@uniroma1.it (V.F.); luigi.celani@uniroma1.it (L.C.); erica.binetti@uniroma1.it (E.B.); battistini.1586873@studenti.uniroma1.it (L.B.); giancarlo.ceccarelli@uniroma1.it (G.C.); claudio.mastroianni@uniroma1.it (C.M.M.); gabriella.dettorre@uniroma1.it (G.d.)

3 Department of General Surgery, Surgical Specialties and Organ Transplantation "Paride Stefanini", Sapienza University of Rome, 00185 Rome, Italy; tommaso.bucci@uniroma1.it

4 Department of Radiological, Oncological and Pathological Sciences, "Sapienza" University of Rome, 00185 Rome, Italy; f.vullo@policlinicoumberto1.it

5 Medical Emergency Unit, Sapienza University of Rome, Policlinico Umberto I, 00185 Rome, Italy; m.alessandroni@policlinicoumberto1.it (M.A.); g.galardo@policlinicoumberto1.it (G.G.)

* Correspondence: a.russo@unicz.it

Abstract: Objectives: COVID-19 may show no peculiar signs and symptoms that may differentiate it from other infective or non-infective etiologies; thus, early recognition and prompt management are crucial to improve survival. The aim of this study was to describe clinical, laboratory, and radiological characteristics and outcomes of hospitalized COVID-19 patients compared to those with other infective or non-infective etiologies. Methods: We performed a prospective study from March 2020 to February 2021. All patients hospitalized for suspected or confirmed COVID-19 were prospectively recruited. All patients were evaluated according to a predefined protocol for diagnosis of suspected SARS-CoV-2 infection. The primary endpoint was evaluation of clinical, laboratory, and radiological characteristics associated or not with COVID-19 etiology at time of hospitalization in an emergency department. Results: A total of 1036 patients were included in the study: 717 (69\%) patients with confirmed COVID-19 and 319 (31\%) without COVID-19, hospitalized for other causes. The main causes of hospitalization among non-COVID-19 patients were acute heart failure (44\%) and bacterial pneumonia (45.8\%). Overall, 30-day mortality was $9 \%$ among the COVID-19 group and 35\% in the non-COVID-19 group. Multivariate analysis showed variables (fever $>3$ days, dry cough, acute dyspnea, lymphocytes $<1000 \times 10^{3} / \mu \mathrm{L}$, and ferritin $>250 \mathrm{ng} / \mathrm{mL}$ ) independently associated with COVID-19 etiology. A decision tree was elaborated to early detect COVID-19 patients in the emergency department. Finally, Kaplan-Meier curves on 30-day survival in COVID-19 patients during the first wave (March-May 2020, $n=289$ patients) and the second wave (October-February 2021, $n=428$ patients) showed differences between the two study periods ( $p=0.021$ ). Conclusions: Patients with confirmed diagnosis of COVID-19 may show peculiar characteristics at time of hospitalization that could help physicians to distinguish from other infective or non-infective etiologies. Finally, a different 30-day mortality rate was observed during different periods of the pandemic.

Keywords: SARS-CoV-2; COVID-19; decision tree; acute respiratory failure; fever; mortality 


\section{Introduction}

Infection caused by severe acute respiratory coronavirus-2 (SARS-CoV-2) in humans was first described in Wuhan, China, in December 2019 [1,2]. As a consequence of the pandemic, the clinical understanding of the disease has deepened. As a matter of fact, an early recognition and prompt management of coronavirus disease-19 (COVID-19) in hospitalized patients is crucial to improve survival, but COVID-19 infection may not have peculiar signs and symptoms that can differentiate this infection from other infective or non-infective causes of acute respiratory failure and/or fever [3].

In the last months, a huge number of experiences have been published, but despite this, still a large amount of information about this serious disease is missing. To date, all patients admitted to emergency departments with acute respiratory failure and/or fever should be considered as a suspected SARS-CoV-2 infection [4-7]. A previous experience about the first months of pandemic was already reported (RESILIENCY study I) [8]; the 653 patients from RESILIENCY I have been also included in this analysis.

The main objective of this study was to describe clinical, laboratory, and radiological characteristics and outcomes of hospitalized COVID-19 patients compared to those with other infective or non-infective etiologies. We also reported data about 30-day survival in all COVID-19 patients and during the first wave (March-May 2020) and the second wave (October-February 2021) of the pandemic in Italy.

\section{Materials and Methods}

We performed a prospective, multicenter study (RESILIENCY study) from March 2020 to February 2021. During the study period, patients hospitalized for suspected or confirmed COVID-19 infection were prospectively recruited in 1 large teaching hospital in Rome, Italy. Patients with suspected COVID-19 were admitted to the hospital in case of fever and/or hypoxemic respiratory failure $\left(\mathrm{PaO}_{2}<60 \mathrm{mmHg}\right.$ at rest in ambient air) or of exacerbation of underlying diseases or severe symptoms not manageable outside the hospital. Patients aged $<18$ years were excluded. Patients were enrolled in 2 different periods: 1st wave (March-May 2020) and 2nd wave (October-February 2021) of pandemic in Italy.

All patients were evaluated in a dedicated emergency department by a dedicated staff of infectious disease specialists that identified patients with SARS-CoV-2 infection as soon as they arrived at the hospital, followed the patients during the hospital stay, and collected all data prospectively without interfering with the therapeutic decisions. The prospective nature of the study was based on the consecutive enrollment of patients. However, during the first wave, all patients with other etiologies (not COVID-19) were not systematically enrolled in this study. A dedicated emergency department that admitted all patients with fever and/or acute respiratory failure started only during the second wave.

\subsection{Data Collection and Definitions}

The following data were collected from the patients' medical records at the time of suspected COVID-19 diagnosis in the emergency department: demographics, underlying diseases, clinical, laboratory and radiological findings, treatments, COVID-19-related complications, therapies (including antibiotics, steroids, low-molecular-weight heparin (LMWH), and remdesivir use), and outcome. All complete data were retrieved from an online database for anonymous and automatic data collection.

A confirmed case of COVID-19 was defined by a positive result of reverse transcriptase polymerase chain reaction (RT-PCR) assay of a respiratory sample.

Non-invasive respiratory support techniques included high flow nasal cannulae (HFNC), continuous positive airway pressure, and non-invasive positive pressure ventilation. 


\subsection{Main Outcome Measures}

The primary outcome measures included demographics, underlying diseases, clinical presentation of patients affected or not by COVID-19, treatments, intensive care unit (ICU) admission, and all-cause 30-day mortality.

\subsection{Microbiology}

SARS-CoV-2 was identified through real-time (RT)-PCR performed on nasopharyngeal swabs. Respiratory samples were tested using RT-PCR targeted at open reading frame $1 \mathrm{ab}$ $(\mathrm{ORF} 1 \mathrm{ab})$ and nucleocapsid protein $(\mathrm{N})$ genes. A cycle threshold $(\mathrm{Ct})$ value $<37$ defined a positive test, while a $\mathrm{Ct}$ value $\geq 40$ defined a negative result.

Possible co-infection with influenza or other respiratory viruses was ruled out by means of multiplex RT-PCR on the same respiratory sample (Allplex TM Respiratory Panel Assay, Seoul, South Korea).

Bacterial and/or fungal cultures to identify such pathogens were collected according to physicians' judgment, and micro-organisms were identified with matrix-assisted laser desorption/ionization-time of flight (MALDI-TOF) and tested for antimicrobial susceptibility with Vitek 2 automated system (bioMérieux, Marcy l'Etoile, France).

\subsection{Statistical Analysis}

Primary endpoint was evaluation of risk factors associated or not with COVID-19 infection at the time of hospitalization; secondary endpoint was the evaluation of variables associated with outcome (death or survival) at 30 days.

We developed a decision tree-based predicting model $[9,10]$. The algorithm has been coded in Python 3.5. As splitting criteria, we used entropy. In order to assess the quality of the model, we performed a 10-fold cross-validation test, considering the sensitivity and specificity as performance measures. Precisely, the algorithm processes the database containing all patients with suspected COVID-19 infection through a progressive sequence of tests. These tests, with a positive or negative outcome for the categorical variable and greater or smaller than a given threshold for the continuous variables, were performed by the algorithm on all the instances in the database. Subsequently, we asked the algorithm to provide the variables that split the samples into classes (COVID-19 and non-COVID-19). For our specific cohort, as the first test, the algorithm selected the variable serum ferritin; this variable divides the root (i.e., the set of all patients) into three leaves: a pure leaf, patients with ferritin more than $346 / \mu \mathrm{L}$, consisting of 28 non-COVID-19 and 144 COVID-19 patients; with ferritin between $209 / \mu \mathrm{L}$ and $346 / \mu \mathrm{L}$, consisting of 22 non-COVID-19 and 225 COVID-19 patients; and an impure leaf, patients with ferritin less than $209 / \mu \mathrm{L}$, consisting of 44 non-COVID-19 and 59 COVID-19 patients. Then, we asked the algorithm to choose a new test, namely, the variable that most divided COVID-19 from non-COVID-19 patients among these subjects. The algorithm identified the variable lymphocytes lesser than equal $1000 \times 10^{3} / \mu \mathrm{L}$, presence of fever $>3$ days and cough. The new cases of suspected COVID19 infection will be processed with the built model to predict the probability of developing COVID-19 infection as follows: the patient will be tested according to the sequence of questions identified by the tree and eventually lie in a leaf that will determine the class (COVID-19 or non-COVID-19).

Other statistical analyses were performed using SPSS Statistics version 21.0 (IBM Corp., Armonk, NY, USA) or Microsoft Excel (Office 2019). Quantitative variables are presented using the mean and the standard deviation (SD) if they are normally distributed or the median and the interquartile range (IQR: 25-75\%) if they follow a non-normal distribution. Normal distribution was assessed using the Kolmogorov-Smirnov test. The differences between groups were assessed with the chi-squared test or Fisher's exact test (for categorical variables) and the two-tailed Student's $t$-test or Mann-Whitney test (for continuous variables), as appropriate. Missing data for each variable were excluded from the denominator. Univariable analysis was used to identify risk factors for COVID-19 or non-COVID-19 etiology and predictors of all cause 30-day mortality. Baseline predictors 
possibly associated with the outcome at univariable comparison were considered for multivariable logistic regression to estimate adjusted odds ratios (ORs) and $95 \%$ confidence intervals ( $95 \% \mathrm{CI}$ ) for the risk factors including the confounding factors (i.e., age, gender). A stepwise backward selection approach was used to select the predictors to include in the final multivariable model. Survival was analyzed by Kaplan-Meier curves and the statistical significance of the differences between the 2 groups was assessed using the log-rank test.

\section{Results}

Overall, during study period 1036 patients were consecutively included in the study: $717(69 \%)$ patients with confirmed COVID-19 and 319 (31\%) without COVID-19, hospitalized for other causes. The main causes of hospitalization, among non-COVID-19 patients, were acute heart failure (44\%), bacterial pneumonia ( $45.8 \%)$, pulmonary embolism $(6.9 \%)$, and other (3.3\%). Overall, $136(18.9 \%)$ patients of COVID-19 group and $87(27.2 \%)$ hospitalized for other causes were admitted to intensive care unit.

In Table 1 is reported comparison between patients affected or not by COVID-19 in the emergency department. No difference was reported about male sex, while higher age (75.3 vs. 64.1 years, $p<0.001)$, procalcitonin value ( 2.6 vs. $0.9 \mathrm{ng} / \mathrm{mL}, p=0.002)$, and bacterial co-infection ( $28 \%$ vs. $20 \%, p=0.004)$ were more frequently observed in non-COVID-19 group. Conversely, higher mean day from symptoms to RT-PCR test (4 vs. $2, p=0.002$ ), coexisting comorbidities ( $55 \%$ vs. $27 \%, p<0.001)$, serum ferritin $(458$ vs. $343 \mathrm{ng} / \mathrm{mL}$, $p=0.013)$, fever $>3$ days ( $77 \%$ vs. $12 \%, p<0.001)$, and dry cough $(47 \%$ vs. $16 \%, p<0.001)$ were more frequently reported in the COVID-19 group.

Table 1. Comparison between COVID-19-positive and -negative patients in the emergency department.

\begin{tabular}{|c|c|c|c|}
\hline Variables & $\begin{array}{c}\text { Non-COVID-19 } \\
\quad n=319\end{array}$ & $\begin{array}{c}\text { COVID-19 } \\
n=717\end{array}$ & $p$-Value \\
\hline Male sex & $199(62 \%)$ & $446(62 \%)$ & 0.956 \\
\hline Age (years), median (IQR: $25-75 \%) \pm S D$ & $75.3 \pm 14.4$ & $64.1 \pm 17.1$ & $<0.001$ \\
\hline $\begin{array}{l}\text { Days from symptoms to RT-PCR test, median } \\
\text { (IQR: } 25-75 \%)\end{array}$ & $2(1-5)$ & $4(1-7)$ & 0.002 \\
\hline Coexisting comorbidities, $n(\%)$ & $286(89.6 \%)$ & $206(28.7 \%)$ & $<0.001$ \\
\hline Cardiovascular disease, $n(\%)$ & $248(78 \%)$ & $57(8 \%)$ & $<0.001$ \\
\hline COPD, $n(\%)$ & $163(51 \%)$ & $60(8 \%)$ & $<0.001$ \\
\hline Chronic renal disease, $n(\%)$ & $100(31 \%)$ & $37(5 \%)$ & $<0.001$ \\
\hline Cirrhosis, $n(\%)$ & $64(20 \%)$ & $17(2 \%)$ & $<0.001$ \\
\hline Diabetes, $n(\%)$ & $27(8 \%)$ & $77(11 \%)$ & $<0.001$ \\
\hline Solid lung cancer, $n(\%)$ & $61(19 \%)$ & $6(1 \%)$ & $<0.001$ \\
\hline \multicolumn{4}{|l|}{ Clinical features and radiological findings on admission } \\
\hline Fever $>3$ days, $n(\%)$ & $39(12 \%)$ & $554(77 \%)$ & $<0.001$ \\
\hline Dry cough, $n(\%)$ & $51(16 \%)$ & $334(47 \%)$ & $<0.001$ \\
\hline Acute dyspnea, $n(\%)$ & $90(28 \%)$ & $372(52 \%)$ & $<0.002$ \\
\hline $\begin{array}{l}\text { Gastrointestinal symptoms (diarrhea, } \\
\text { abdominal discomfort, nausea, vomiting) }\end{array}$ & $44(14 \%)$ & $107(15 \%)$ & 0.675 \\
\hline Fatigue, $n(\%)$ & $189(59 \%)$ & $109(15 \%)$ & $<0.001$ \\
\hline Pharyngodynia, $n(\%)$ & $16(5 \%)$ & $38(5 \%)$ & 1.000 \\
\hline Rhinitis, $n(\%)$ & $184(58 \%)$ & $259(36 \%)$ & $<0.001$ \\
\hline Arthralgia/myalgia, $n(\%)$ & $16(5 \%)$ & $73(10 \%)$ & 0.007 \\
\hline
\end{tabular}


Table 1. Cont.

\begin{tabular}{|c|c|c|c|}
\hline Variables & $\begin{array}{l}\text { Non-COVID-19 } \\
\quad n=319\end{array}$ & $\begin{array}{c}\text { COVID-19 } \\
n=717\end{array}$ & $p$-Value \\
\hline Anosmia, $n(\%)$ & $7(2 \%)$ & $31(4 \%)$ & 0.101 \\
\hline Conjunctivitis, $n(\%)$ & $0(0 \%)$ & $4(1 \%)$ & 0.073 \\
\hline Chest pain, $n(\%)$ & $18(6 \%)$ & $33(5 \%)$ & 0.508 \\
\hline $\begin{array}{l}\text { Signs of overload (limb edema and/or } \\
\text { pulmonary stasis), } n(\%)\end{array}$ & $37(12 \%)$ & $17(2 \%)$ & $<0.001$ \\
\hline Parenchymal thickening, $n(\%)$ & $66(21 \%)$ & $344(48 \%)$ & $<0.001$ \\
\hline Interstitial lung disease, $n(\%)$ & $16(5 \%)$ & $31(4 \%)$ & 0.464 \\
\hline Pleural effusion, $n(\%)$ & $110(34 \%)$ & $191(27 \%)$ & 0.022 \\
\hline Cardiomegaly, $n(\%)$ & $99(31 \%)$ & $232(32 \%)$ & 0.750 \\
\hline Bronchiectasis/emphysema, $n(\%)$ & $27(24 \%)$ & $50(15 \%)$ & 0.013 \\
\hline \multicolumn{4}{|l|}{ Laboratory findings } \\
\hline WBC $\left(\times 10^{3} / \mu \mathrm{L}\right)$, median (IQR: $\left.25-75 \%\right)$ & $7.5(6.4-12.3)$ & $6.1(4.5-8.8)$ & $<0.001$ \\
\hline Neutrophils $\times 10^{3} / \mu \mathrm{L}$, median (IQR: $25-75 \%$ ) & $5.6(3.8-9.4)$ & $4.4(3-7.1)$ & 0.368 \\
\hline Lymphocytes $\times 10^{3} / \mu \mathrm{L}$, median (IQR: $25-75 \%$ ) & $1.1(0.8-1.8)$ & $0.9(0.6-1.2)$ & $<0.001$ \\
\hline Platelets $\times 10^{3} / \mu \mathrm{L}$, median (IQR: $25-75 \%$ ) & $232(192-305)$ & $205(159-266)$ & $<0.001$ \\
\hline D-dimer ng/mL, median (IQR: 25-75\%) & $820(367-1322)$ & $631(340-1242)$ & 0.178 \\
\hline Serum ferritin ng/mL, median (IQR: 25-75\%) & $343(120-811)$ & $458(219-813)$ & 0.013 \\
\hline Procalcitonin ng/mL, median (IQR: 25-75\%) & $2.6(0.4-3)$ & $0.9(0.1-1.5)$ & 0.002 \\
\hline $\mathrm{LDH} \mathrm{mU} / \mathrm{mL}$, mean $\pm \mathrm{SD}$ & $404 \pm 191$ & $317 \pm 147$ & $<0.001$ \\
\hline CPK U /L, median (IQR: 25-75\%) & $74(48-170)$ & $89(52-160)$ & 0.010 \\
\hline Lactate $\mathrm{mmol} / \mathrm{L}$, mean $\pm \mathrm{SD}$ & $1.8 \pm 1.4$ & $1.3 \pm 0.8$ & $<0.001$ \\
\hline C-reactive protein mg/dL, median (IQR: 25-75\%) & $10.3(6.5-13)$ & $4(1.3-9.8)$ & 0.022 \\
\hline $\begin{array}{l}\text { Alanine aminotransferase } \mathrm{U} / \mathrm{L} \text {, median } \\
\text { (IQR: } 25-75 \% \text { ) }\end{array}$ & $28(20-46)$ & $29(20-42)$ & 0.258 \\
\hline $\begin{array}{l}\text { Aspartate aminotransferase U/L, median } \\
\text { (IQR: } 25-75 \%)\end{array}$ & $26(18-45)$ & $22(16-34)$ & 0.015 \\
\hline $\mathrm{PaO}_{2} / \mathrm{FiO}_{2}$, mean $\pm \mathrm{SD}$ & $326 \pm 106$ & $317 \pm 114$ & 0.010 \\
\hline Bacterial co-infection, $n(\%)$ & $89(28 \%)$ & $144(20 \%)$ & 0.004 \\
\hline Days of hospitalization, median (IQR: $25-75 \%$ ) & $12(9-19)$ & $12(8-19)$ & 0.376 \\
\hline $\begin{array}{l}\text { Days to RT-PCR negative test, median } \\
\text { (IQR: } 25-75 \% \text { ) }\end{array}$ & - & $14(11-23)$ & - \\
\hline
\end{tabular}

SD: standard deviation; COPD: chronic obstructive pulmonary disease; WBC: white blood cells; LDH: lactate dehydrogenase; CPK: creatine phosphokinase.

Need of oxygen supplement, non-invasive or invasive ventilation, and 30-day mortality are reported in Table 2 . No differences were reported about rate of invasive ventilation. Patients in the non-COVID-19 group were more frequently treated with HFNC/NIV (39\% vs. $18 \%, p<0.001$ ), while 30 -day mortality was $9 \%$ in the COVID-19 group and $35 \%$ in the non-COVID-19 group $(p<0.001)$. Mortality rate in COVID-19 group was also calculated using $4 \mathrm{C}$ Mortality Score [11]: in patients with 0-3 points, a 30-day mortality of $1.2 \%$ was reported, with $4-8$ points $-12.3 \%$, with $9-14$ points- $31.7 \%$, and $\geq 15$ points- $54.8 \%$. 
Table 2. Need of oxygen supplement, non-invasive or invasive ventilation, and 30-day mortality.

\begin{tabular}{lccc}
\hline \multicolumn{1}{c}{ Variables } & $\begin{array}{c}\text { Non-COVID-19 } \\
n=319\end{array}$ & $\begin{array}{c}\text { COVID-19 } \\
n=717\end{array}$ & $p$-Value \\
\hline Invasive ventilation, $n(\%)$ & $27(8 \%)$ & $36(5 \%)$ & 0.059 \\
\hline Low oxygen flow or room air, $n(\%)$ & $167(52 \%)$ & $480(67 \%)$ & $<0.001$ \\
\hline HFNC/NIV, $n(\%)$ & $126(39 \%)$ & $127(18 \%)$ & $<0.001$ \\
\hline 30-day mortality, $n(\%)$ & $111(35 \%)$ & $61(9 \%)$ & $<0.001$ \\
\hline
\end{tabular}

HFNC: high flow nasal cannula; NIV: non-invasive ventilation.

Multivariable analysis (see Table 3 ) about risk factors for SARS-CoV-2 etiology showed that fever $>3$ days (OR 14, C195\% 9.06-20.07, $p<0.001$ ), dry cough (OR 4.06, C195\% 3.03-6.05, $p<0.001$ ), acute dyspnea (OR 2.08, CI95\% 2.02-3.07, $p<0.001$ ), lymphocytes $<1000 \times 10^{3} / \mu \mathrm{L}$ (OR 1.05, CI95\% 1.01-2, $p=0.027$ ), and ferritin > $250 \mathrm{ng} / \mathrm{mL}$ (OR 1.05, CI5\% 1.02-1.08, $p=0.039$ ) were independently associated with COVID-19 at time of hospitalization.

Table 3. Multivariate analysis about risk factors associated with SARS-CoV-2 etiology.

\begin{tabular}{cccc}
\hline Variables & OR & CI95\% & $p$-Value \\
\hline Fever $>3$ days & 14 & $9.06-20.07$ & $<0.001$ \\
\hline Dry cough & 4.06 & $3.03-6.05$ & $<0.001$ \\
\hline Acute dyspnea & 2.08 & $2.02-3.07$ & $<0.001$ \\
\hline Lymphocytes $<1000 \times 10^{3} / \mu \mathrm{L}$ & 1.05 & $1.01-2$ & 0.027 \\
\hline Ferritin $>250 \mathrm{ng} / \mathrm{mL}$ & 1.05 & $1.02-1.08$ & 0.039 \\
\hline
\end{tabular}

Then, we developed a risk predictive model of COVID-19 using a machine learning technique: decision-making tree to early detect COVID-19 patients in the emergency department. The predictive model highlighted the following variables: serum ferritin, lymphocytes count $<1000 / \mu \mathrm{L}$, fever $>3$ days, and dry cough (see Figure 1 ). Overall, the sensitivity reached 0.990 (CI95\%: $0.964-100)$, the specificity reached 0.863 (CI95\%: 0.737-0.943), and the total accuracy reached 0.954 (CI95\%: 0.907-0.981).

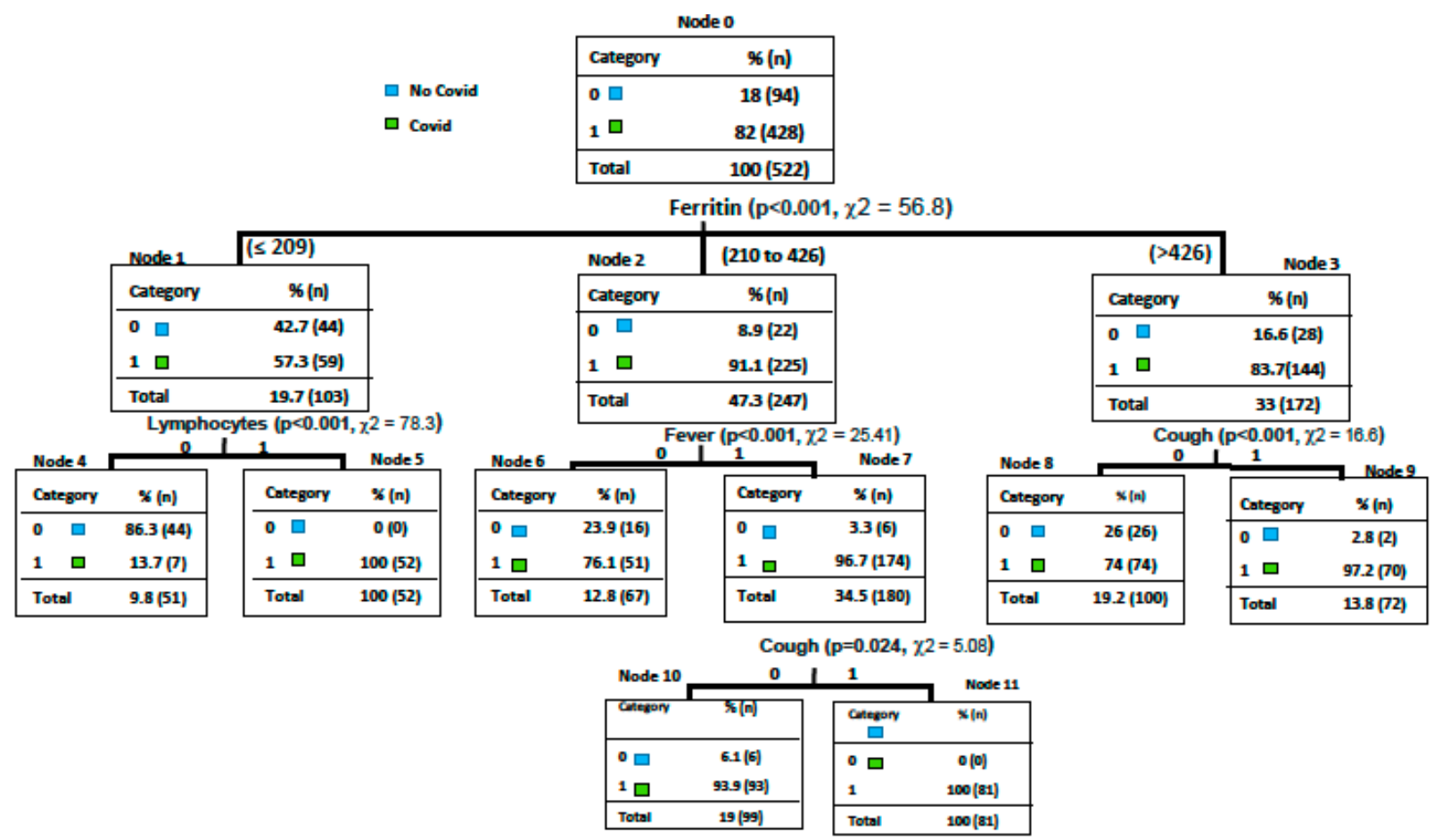

Figure 1. Decision tree to early detect suspected COVID-19 patients in the emergency department. 
Finally, multivariable analysis about risk factors associated with 30-day mortality in COVID-19 patients is reported in Table 4. Age $\geq 65$ years (OR 4.23, CI95\% 2.83-6.33, $p<0.001$ ) and ICU admission (OR 2.51, CI95\% 1.44-4.4, $p=0.001$ ) were independently associated with 30-day mortality; conversely, no comorbidities (OR 0.03, CI95\% $0.02-$ $0.04, p<0.001$ ), steroids (OR 0.16, CI95\% 0.1-0.25, $p<0.001$ ), LMWH (OR 0.2, CI95\% $0.12-0.32, p<0.001$ ), or remdesivir (OR 0.26 , CI95\% $0.15-0.43, p<0.001$ ) were associated with 30-day survival.

Table 4. Multivariate analysis about risk factors associated with 30-day mortality in COVID-19 patients.

\begin{tabular}{cccc}
\hline Variables & OR & CI95\% & $p$-Value \\
\hline Age $\geq 65$ years & 4.23 & $2.83-6.33$ & $<0.001$ \\
\hline No comorbidities & 0.03 & $0.02-0.04$ & $<0.001$ \\
\hline Steroids & 0.16 & $0.1-0.25$ & $<0.001$ \\
\hline LMWH & 0.2 & $0.12-0.32$ & $<0.001$ \\
\hline Remdesivir & 0.26 & $0.15-0.43$ & $<0.001$ \\
\hline ICU admission & 2.51 & $1.44-4.4$ & 0.001
\end{tabular}

LMWH: low-molecular-weight heparin; ICU: intensive care unit.

In Figure 2, Kaplan-Meier curves on 30-day survival in COVID-19 patients during the first wave (March-May 2020, $n=289$ patients) and the second wave (October-February $2021, n=428$ patients) showed statistically significant differences between the two study periods (log-rank test $p=0.021$ ).

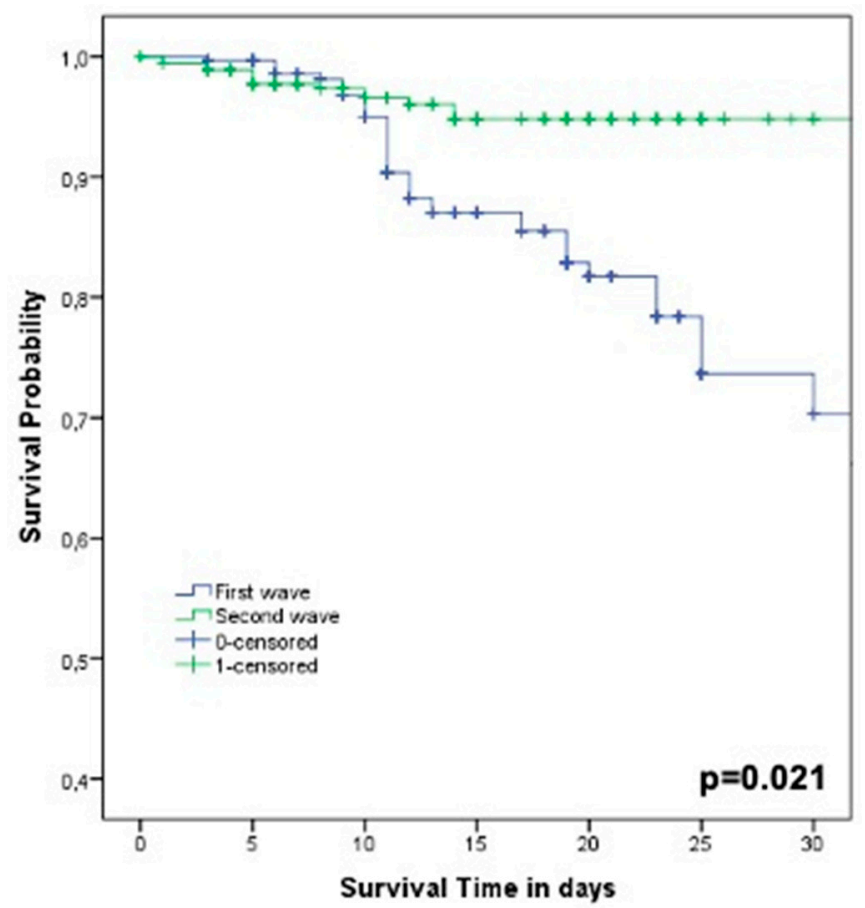

Figure 2. Kaplan-Meier curves on 30-day survival in COVID-19 patients during the first wave (March-May 2020, $n=289$ patients) and the second wave (October-February 2021, $n=428$ patients).

\section{Discussion}

Data from this prospective study highlighted peculiar characteristics associated with SARS-CoV-2 etiology in suspected COVID-19 patients at the emergency department. The findings of the present study, conducted in a large hospital in Italy, showed that the prompt identification of specific clinical characteristics (such as acute dyspnea, dry cough, and duration of fever $>3$ days) and laboratory findings (such as lymphocytopenia and serum 
ferritin) can help physicians to distinguish between COVID-19 or other etiologies. As previously reported, the application of a standard approach to management of patients with acute respiratory failure and/or fever [8] associated with the knowledge of clinical and laboratory characteristics of COVID-19 (see Figure 2) can early drive physicians to therapeutic choices. Of importance, our data confirmed that age $\geq 65$ years and ICU admission showed an independent association with all-cause 30-day mortality, confirming previous observations [3,4]. Finally, the use of steroids, LMWH, and remdesivir was associated with survival [12-14].

Our study has several limitations. First, it was an observational analysis, and we might have missed predictors that could potentially influence the clinical outcome of the patients. Second, this study was performed in a single geographical area of Italy, and the results may not be necessarily representative of other centers. Third, some data were missing for certain patients included in this study; moreover, from November 2020, our institution established a dedicated emergency department that took care of all patients with suspected COVID-19; then, in the previous months (first wave), the patients with other etiologies (not COVID-19) were not systematically enrolled. The compared groups are heterogenous considering different epidemiologic dynamics between the first and second waves. Studies have shown that in the first wave, mostly older people died, while patients in the second wave were younger and the duration of hospitalization and case fatality rate were lower than those in the first wave $[15,16]$. Finally, no definitive data about the impact of therapies on mortality in COVID-19 patients can be extracted from this analysis.

Data from a large cohort of patients in Moscow [17] showed that typically fever, fatigue, cough, and shortness of breath were the most frequent symptoms observed in suspected COVID-19 patients, in agreement with other studies in other countries [18,19]. Moreover, lymphocytopenia has been previously reported to be associated with higher severity and mortality in COVID-19 patients [20]. Of interest, data from an Italian cohort demonstrated that ferritin levels over the 25th percentile are associated with a more severe pulmonary involvement, independently of age and gender [21]. An early risk assessment for COVID-19 patients from the emergency department, using machine learning, showed that age and measures of oxygenation status were primary indicators of poor patient outcomes [22].

In our cohort, CT findings in COVID-19 patients were frequently indistinguishable from other etiologies, such as acute heart failure, bacterial pneumonia, or pulmonary embolism. Considering typical radiological findings in COVID-19, it is important to underline that in this population, especially in the first stage, could be present only extrapulmonary manifestations with a normal CT finding [23]. In this scenario, it is important to underline that a negative RT-PCR test result does not exclude the possibility of COVID-19, and repeated testing and sampling was shown to improve the sensitivity of RT-PCR [24]. A decision tree classifier for a pre-screening of patients and to conduct triage and fast-track decision, before RT-PCR, were proposed using chest X-ray radiography [25]. Other approaches for diagnosis and to estimate the risk of mortality were reported in order to prioritize medical care and resources $[26,27]$. Then, a rigorous application of a standard approach to management of suspected COVID-19, associated with clinical and laboratoristic findings as reported in our decision tree, could help physicians in emergency departments.

Of importance, data about 30-day mortality could explain the difference rate of survival $(p=0.021)$ during the first wave (March-May 2020) and the second wave (OctoberFebruary 2021). A peculiar aspect of COVID-19 patients, especially during the second wave, was the widely use of steroids, LMWH, and remdesivir that could have modified the outcomes of this population [28]. Data in literature showed that the use of dexamethasone resulted in lower 28-day mortality, especially in patients receiving invasive mechanical ventilation $[29,30]$, while important observations were reported about the role of LMWH in survival of COVID-19 patients [31,32]. Of interest, we also observed a different rate of thromboembolic events during the first wave (34.9\%) and the second wave (15.7\%). Finally, different data were reported worldwide regarding the efficacy of remdesivir, taking 
into account different outcomes [33,34]. Moreover, our analysis was not performed to weigh all the possible therapeutic confounders: most patients were hospitalized with an extramurally positive test, and a low percentage of patients, with clinical stability, were discharged with a positive test and transferred to "COVID hotels".

\section{Conclusions}

In conclusion, COVID-19 syndrome is characterized by a heterogeneous clinical, laboratoristic, and radiological presentation, especially at its onset. However, our data showed that patients with a confirmed diagnosis of COVID-19 can show peculiar characteristics at the time of hospitalization that could help physicians to distinguish from other infective or non-infective etiologies [35,36]. Considering the application of a standard approach to management of patients with acute respiratory failure and/or fever, the knowledge of clinical and laboratory characteristics of COVID-19 can drive therapeutic choices early on [37]. We developed a decision tree to detect peculiar characteristics associated with SARS-CoV-2 etiology in suspected COVID-19 patients at an emergency department. However, further larger studies are mandatory to confirm these observations and to validate the decision tree.

Author Contributions: Conceived and designed study: A.R., G.d. Performed data collection: A.R., E.G.C., V.F., T.B., F.V., L.C., E.B., L.B., G.C., M.A., G.G., C.M.M. Analyzed data: A.R., C.B. Wrote the paper: A.R., C.B., E.G.C. All authors have read and agreed to the published version of the manuscript.

Funding: This research received no external funding.

Institutional Review Board Statement: The study was conducted according to the guidelines of the Declaration of Helsinki and approved by the Ethics Committee of Sapienza University of Rome, number $321 / 2020$ of $04 / 24 / 2020$.

Informed Consent Statement: Patient consent was waived due to the observational design of the study.

Data Availability Statement: Data will be available on request by email to alessandro.russo1982@ gmail.com.

Conflicts of Interest: The authors declare no conflict of interest.

\section{References}

1. Huang, C.; Wang, Y.; Li, X.; Ren, L.; Zhao, J.; Hu, Y.; Zhang., L.; Fan, G.; Xu, J.; Gu, X.; et al. Clinical features of patients infected with 2019 novel coronavirus in Wuhan, China. Lancet 2020, 395, 497-506. [CrossRef]

2. Bassetti, M.; Vena, A.; Giacobbe, D.R. The novel Chinese coronavirus (2019-nCoV) infections: Challenges for fighting the storm. Eur. J. Clin. Investig. 2020, 50, e13209. [CrossRef]

3. Zhou, F.; Yu, T.; Du, R.; Fan, G.; Liu, Y.; Liu, Z.; Xiang, J.; Wang, Y.; Song, B.; Gu, X.; et al. Clinical course and risk factors for mortality of adult inpatients with COVID-19 in Wuhan, China: A retrospective cohort study. Lancet 2020, 395, 1054-1062. [CrossRef]

4. Vena, A.; Giacobbe, D.R.; Di Biagio, A.; Mikulska, M.; Taramasso, L.; De Maria, A.; Ball, L.; Brunetti, I.; Loconte, M.; Patroniti, N.A.; et al. Clinical characteristics, management and in-hospital mortality of patients with coronavirus disease 2019 in Genoa, Italy. Clin. Microbiol. Infect. 2020, 26, 1537-1544. [CrossRef] [PubMed]

5. Bartoletti, M.; Giannella, M.; Scudeller, L.; Tedeschi, S.; Rinaldi, M.; Bussini, L.; Fornaro, G.; Pancaldi, L.; Pasquini, Z.; Trapani, F.; et al. Development and validation of a prediction model for severe respiratory failure in hospitalized patients with SARS-CoV-2 infection: A multicentre cohort study (PREDI-CO study). Clin. Microbiol. Infect. 2020, 26, 1545-1553. [CrossRef] [PubMed]

6. Liang, W.H.; Guan, W.J.; Li, C.C.; Li, Y.M.; Liang, H.R.; Zhao, Y.; Liu, X.; Sang, L.; Chen, R.; Tang, C.; et al. Clinical characteristics and outcomes of hospitalised patients with COVID-19 treated in Hubei (epicenter) and outside Hubei (non-epicenter): A Nationwide Analysis of China. Eur. Respir. J. 2020, 55, 2000562. [CrossRef]

7. Grasselli, G.; Zangrillo, A.; Zanella, A.; Antonelli, M.; Cabrini, L.; Castelli, A.; Cereda, D.; Coluccelli, A.; Foti, G.; Fumagalli, R.; et al. Network, Baseline Characteristics and Outcomes of 1591 Patients Infected with SARS-CoV-2 Admitted to ICUs of the Lombardy Region, Italy. JAMA 2020, 323, 1574-1581. [CrossRef]

8. Russo, A.; Bellelli, V.; Ceccarelli, G.; Marincola Cattaneo, F.; Bianchi, L.; Pierro, R.; Russo, R.; Steffanina, A.; Pugliese, F.; Mastroianni, C.M.; et al. Comparison Between Hospitalized Patients Affected or Not Affected by Coronavirus Disease 2019. Clin. Infect. Dis. 2021, 72, e1158-e1159. [CrossRef]

9. Safavian, S.R.; Landgrebe, D. A survey of decision tree classifier methodology. IEEE Trans. Syst. Man Cybern. 1991, 21, 660-674. [CrossRef] 
10. Kononenko, I. Machine learning for medical diagnosis: History, state of the art and perspective. Artif. Intell. Med. 2001, 23, 89-109. [CrossRef]

11. Knight, S.R.; Ho, A.; Pius, R.; Buchan, I.; Carson, G.; Drake, T.M.; Dunning, J.; Fairfield, C.J.; Gamble, C.; Green, C.A.; et al. Risk stratification of patients admitted to hospital with covid-19 using the ISARIC WHO Clinical Characterisation Protocol: Development and validation of the 4C Mortality Score. BMJ 2020, 370, m3339, Erratum in BMJ 2020, 371, m4334. [CrossRef]

12. Gozzo, L.; Viale, P.; Longo, L.; Vitale, D.C.; Drago, F. The Potential Role of Heparin in Patients with COVID-19: Beyond the Anticoagulant Effect. A Review. Front. Pharm. 2020, 11, 1307. [CrossRef]

13. Paolisso, P.; Bergamaschi, L.; D’Angelo, E.C.; Donati, F.; Giannella, M.; Tedeschi, S.; Pascale, R.; Bartoletti, M.; Tesini, G.; Biffi, M.; et al. Preliminary Experience with Low Molecular Weight Heparin Strategy in COVID-19 Patients. Front. Pharm. 2020, 11, 1124. [CrossRef] [PubMed]

14. Mehta, P.; McAuley, D.F.; Brown, M.; Sanchez, E.; Tattersall, R.S.; Manson, J.J.U.K. Hlh Across Speciality Collaboration, COVID-19: Consider cytokine storm syndromes and immunosuppression. Lancet 2020, 395, 1033-1034. [CrossRef]

15. Iftimie, S.; López-Azcona, A.F.; Vallverdú, I.; Hernández-Flix, S.; de Febrer, G.; Parra, S.; Hernández-Aguilera, A.; Riu, F.; Joven, J.; Andreychuk, N.; et al. First and second waves of coronavirus disease-19: A comparative study in hospitalized patients in Reus, Spain. PLoS ONE 2021, 16, e0248029. [CrossRef] [PubMed]

16. Kontis, V.; Bennett, J.E.; Rashid, T.; Parks, R.M.; Pearson-Stuttard, J.; Guillot, M.; Asaria, P.; Zhou, B.; Battaglini, M.; Corsetti, G.; et al. Magnitude, demographics and dynamics of the effect of the first wave of the COVID-19 pandemic on all-cause mortality in 21 industrialized countries. Nat. Med. 2020, 26, 1919-1928, Erratum in Nat Med. 2021, 27, 562. [CrossRef] [PubMed]

17. Munblit, D.; Nekliudov, N.A.; Bugaeva, P.; Blyuss, O.; Kislova, M.; Listovskaya, E.; Gamirova, A.; Shikhaleva, A.; Belyaev, V.; Timashev, P.; et al. StopCOVID cohort: An observational study of 3,480 patients admitted to the Sechenov University hospital network in Moscow city for suspected COVID-19 infection. Clin. Infect. Dis. 2020, 73, ciaa1535. [CrossRef] [PubMed]

18. Docherty, A.B.; Harrison, E.M.; Green, C.A.; Hardwick, H.E.; Pius, R.; Norman, L.; Holden, K.A.; Read, J.M.; Dondelinger, F.; Carson, G.; et al. Features of 20133 UK patients in hospital with covid-19 using the ISARIC WHO Clinical Characterisation Protocol: Prospective observational cohort study. BMJ 2020, 369, m1985. [CrossRef] [PubMed]

19. Guan, W.J.; Ni, Z.Y.; Hu, Y.; Liang, W.; Ou, C.; He, J.; Liu, L.; Shan, H.; Lei, C.; Hui, D.S.C.; et al. Clinical Characteristics of Coronavirus Disease 2019 in China. N. Engl. J. Med. 2020, 382, 1708-1720. [CrossRef] [PubMed]

20. Chan, A.S.; Rout, A. Use of Neutrophil-to-Lymphocyte and Platelet-to-Lymphocyte Ratios in COVID-19. J. Clin. Med. Res. 2020, 12, 448-453. [CrossRef]

21. Carubbi, F.; Salvati, L.; Alunno, A.; Maggi, F.; Borghi, E.; Mariani, R.; Mai, F.; Paoloni, M.; Ferri, C.; Desideri, G.; et al. Ferritin is associated with the severity of lung involvement but not with worse prognosis in patients with COVID-19: Data from two Italian COVID-19 units. Sci. Rep. 2021, 11, 4863. [CrossRef] [PubMed]

22. Heldt, F.S.; Vizcaychipi, M.P.; Peacock, S.; Cinelli, M.; McLachlan, L.; Andreotti, F.; Jovanović, S.; Dürichen, R.; Lipunova, N.; Fletcher, R.A.; et al. Early risk assessment for COVID-19 patients from emergency department data using machine learning. Sci. Rep. 2021, 11, 4200. [CrossRef] [PubMed]

23. Harmon, S.A.; Sanford, T.H.; Xu, S.; Turkbey, E.B.; Roth, H.; Xu, Z.; Yang, D.; Myronenko, A.; Anderson, V.; Amalou, A.; et al. Artificial intelligence for the detection of COVID-19 pneumonia on chest CT using multinational datasets. Nat. Commun. 2020, 11, 4080. [CrossRef] [PubMed]

24. Zhang, J.J.; Cao, Y.Y.; Dong, X.; Wang, B.; Liao, M.; Lin, J.; Yan, Y.; Akdis, C.A.; Gao, Y. Distinct characteristics of COVID-19 patients with initial rRT-PCR-positive and rRT-PCR-negative results for SARS-CoV-2. Allergy 2020, 75, 1809-1812. [CrossRef] [PubMed]

25. Yoo, S.H.; Geng, H.; Chiu, T.L.; Yu, S.K.; Cho, D.C.; Heo, J.; Choi, M.S.; Choi, I.H.; Cung Van, C.; Nhung, N.V.; et al. Deep Learning-Based Decision-Tree Classifier for COVID-19 Diagnosis From Chest X-ray Imaging. Front. Med. 2020, 7, 427. [CrossRef]

26. Pourbagheri-Sigaroodi, A.; Bashash, D.; Fateh, F.; Abolghasemi, H. Laboratory findings in COVID-19 diagnosis and prognosis. Clin. Chim. Acta. 2020, 510, 475-482. [CrossRef]

27. Sánchez-Montañés, M.; Rodríguez-Belenguer, P.; Serrano-López, A.J.; Soria-Olivas, E.; Alakhdar-Mohmara, Y. Machine Learning for Mortality Analysis in Patients with COVID-19. Int. J. Environ. Res. Public Health. 2020, 17, 8386. [CrossRef]

28. Domingo, P.; Pomar, V.; Mur, I.; Castellví, I.; Corominas, H.; de Benito, N. Not all COVID-19 pandemic waves are alike. Clin. Microbiol. Infect. 2021, 27, 1040.e7-1040.e10. [CrossRef] [PubMed]

29. Welte, T.; Ambrose, L.J.; Sibbring, G.C.; Sheikh, S.; Müllerová, H.; Sabir, I. Current evidence for COVID-19 therapies: A systematic literature review. Eur. Respir. Rev. 2021, 30, 200384. [CrossRef] [PubMed]

30. Ko, J.J.; Wu, C.; Mehta, N.; Wald-Dickler, N.; Yang, W.; Qiao, R. A Comparison of Methylprednisolone and Dexamethasone in Intensive Care Patients With COVID-19. J. Intensive Care Med. 2021, 36, 673-680. [CrossRef]

31. Falcone, M.; Tiseo, G.; Barbieri, G.; Galfo, V.; Russo, A.; Virdis, A.; Forfori, F.; Corradi, F.; Guarracino, F.; Carrozzi, L.; et al. Role of Low-Molecular-Weight Heparin in Hospitalized Patients With Severe Acute Respiratory Syndrome Coronavirus 2 Pneumonia: A Prospective Observational Study. Open Forum Infect. Dis. 2020, 7, ofaa563. [CrossRef]

32. Cuker, A.; Tseng, E.K.; Nieuwlaat, R.; Angchaisuksiri, P.; Blair, C.; Dane, K.; Davila, J.; DeSancho, M.T.; Diuguid, D.; Griffin, D.O.; et al. American Society of Hematology 2021 guidelines on the use of anticoagulation for thromboprophylaxis in patients with COVID-19. Blood Adv. 2021, 5, 872-888. [CrossRef] 
33. Olender, S.A.; Perez, K.K.; Go, A.S.; Balani, B.; Price-Haywood, E.G.; Shah, N.S.; Wang, S.; Walunas, T.L.; Swaminathan, S.; Slim, J.; et al. Remdesivir for Severe COVID-19 versus a Cohort Receiving Standard of Care. Clin. Infect. Dis. 2020, ciaa1041. [CrossRef] [PubMed]

34. WHO Solidarity Trial Consortium; Pan, H.; Peto, R.; Henao-Restrepo, A.M.; Preziosi, M.P.; Sathiyamoorthy, V.; Abdool Karim, Q.; Alejandria, M.M.; Hernán-dez García, C.; Kieny, M.P.; et al. Repurposed Antiviral Drugs for Covid-19-Interim WHO Solidarity Trial Results. N. Engl. J. Med. 2021, 384, 497-511.

35. Alhazzani, W.; Moller, M.H.; Arabi, Y.M.; Loeb, M.; Gong, M.N.; Fan, E.; Oczkowski, S.; Levy, M.M.; Derde, L.; Dzierba, A.; et al. Surviving Sepsis Campaign: Guidelines on the Management of Critically Ill Adults with Coronavirus Disease 2019 (COVID-19). Crit. Care Med. 2020, 48, e440-e469. [CrossRef] [PubMed]

36. Bassetti, M.; Giacobbe, D.R.; Aliberti, S.; Barisione, E.; Centanni, S.; De Rosa, F.G.; Di Marco, F.; Gori, A.; Granata, G.; Mikulska, M.; et al. Balancing evidence and frontline experience in the early phases of the COVID-19 pandemic: Current position of the Italian Society of Anti-Infective Therapy (SITA) and the Italian Society of Pulmonology (SIP). Clin. Microbiol. Infect. 2020, 26, 880-894. [CrossRef] [PubMed]

37. Sinha, P.; Calfee, C.S.; Cherian, S.; Brealey, D.; Cutler, S.; King, C.; Killick, C.; Richards, O.; Cheema, Y.; Bailey, C.; et al. Prevalence of phenotypes of acute respiratory distress syndrome in critically ill patients with COVID-19: A prospective observational study. Lancet Respir. Med. 2020, 8, 1209-1218. [CrossRef] 